Saher S Gasgoos

BDS, MSc (Lec.)

Ghada D Al-Sayagh

BDS, MSc (Asst Prof.)

Karam H Jazrawi BDS, MSc (Lec.)

\section{Evaluation of Dental Caries Prevalence among Children in Mosul City Center Using Significant Caries Index}

\author{
Dept of Pedod, orthod, and Prev Dentistry \\ College of Dentistry, University of Mosul \\ Dept of Pedod, orthod, and Prev Dentistry \\ College of Dentistry, University of Mosul \\ Dept of Pedod, orthod, and Prev Dentistry \\ College of Dentistry, University of Mosul
}

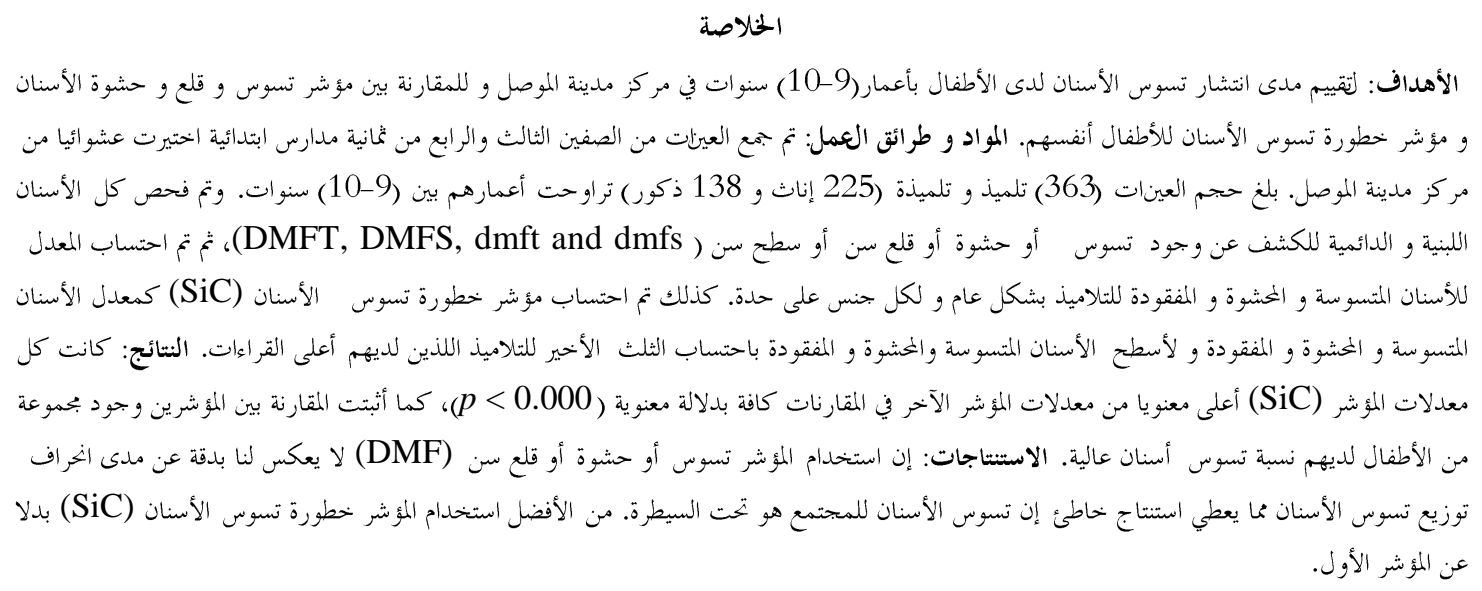

ABSTRACT

Aims of the study: To evaluate the prevalence of dental caries among children aged 9-10 years in Mosul City Center and to compare between traditional index and significant caries index of these students. Materials and Methods: The study sample was obtained from third and fourth class students from eight randomly selected primary schools in Mosul City Center. Sample size was 363 students, 225 females and 138 males. Students' ages were 9 and 10 years. All primary and permanent teeth were examined for the presence of decay, missing or filling teeth/surfaces. Mean DMFT, DMFS, dmft and $\mathrm{dmfs}$ were calculated for the students together and separately for each sex. The mean Significant Caries Index $(\mathrm{SiC})$ was also calculated as the mean DMFT and DMFS of the one third of the students with the highest caries scores. Results: The $\mathrm{SiC}$ index was significantly higher in all comparisons with traditional DMF index $(p<0.000)$. A comparison between the two indices indicated that there is a large children subgroup presented with a high caries rate. Conclusions: The mean DMF values did not accurately reflect the skewed distribution of dental caries leading to incorrect conclusions that the caries rate of the statewide population is under control. It is better to use $\mathrm{SiC}$ index instead of the traditional index.

Key words: Significant Caries Index, DMFT, DMFS.

Gasgoos SS, Al-Sayagh GD, Jazrawi KH. Evaluation of Dental Caries Prevalence among Children in Mosul City Center Using Significant Caries Index. Al-Rafidain Dent J. 2012; 12(1): 191-197.

Received: 25/9/2011 Sent to Referees: 28/9/2011

Accepted for Publication: 13/10/2011

\section{INTRODUCTION}

In 1997, the World Health Assembly has an important goal for oral health in children. The global average of dental caries experience in 12-year-old children should not be higher than 3.0 in the year
2000. When this limit was established in the late 1970s, only few countries had presented reports on a decline of caries prevalence. While many hoped that this goal might be achieved for their country, no solid evidence was available at that time to 
demonstrate if this goal was realistic. ${ }^{(1)}$ By 1995, the average DMFT index in six industrialized Western European countries (Denmark, Finland, Ireland, the Netherlands, Sweden and UK) had fallen below 2.0. ${ }^{(2)}$ Since some detailed scientific papers and abstracts have shown that the DMFT still shows a tendency to decrease, whereas in other papers, the DMFT seems to be bottoming out. Whatever the future may be, for the countries of Western Europe, North America and several countries beyond, most of them English speaking, the original WHO requirement of less than 3.0 DMFT has caused to be a useful yardstick. $^{(1)}$

A detailed analysis of the caries prevalence in many countries has often shown a skewed distribution of the disease: a group of 12-year-olds may have high or very high decayed/missing/filled teeth (DMFT) values, while the rest of the age group shows low DMFT or are totally cariesfree $^{(3-5)}$ Obviously, expressing caries prevalence as the mean DMFT value does not correctly reflect the skewed distribution, leaving high caries groups undiscovered in the population. In order not to lose the positive momentum gained from various oral health programs around the world, and to target the still caries-susceptible individuals in the population, a new index, the significant caries $(\mathrm{SiC})$ index, was introduced in the year 2000 to call attention to those children with the highest scores in each population. ${ }^{(6,7)}$ The $\mathrm{SiC}$ index is calculated by taking the mean DMF of the one-third of the individuals having the highest of DMF values in a given population. $^{(2,4)}$ The use of the SiC index may solve the problem related to skewed caries distribution. ${ }^{(8)}$ In addition, a new goal was proposed: the $\mathrm{SiC}$ index should be less than 3 DMFT among12-year-olds by the year $2015 .^{(4)}$

The purpose of this study was to evaluate the prevalence of dental caries among students aged 9-10 years in Mosul City center and to compare between traditional index and $\mathrm{SiC}$ index of these students.

\section{MATERIALS AND METHODS}

The study sample was obtained from third and fourth class students from eight ran- domly selected primary schools in Mosul City Center. Sample size was 363 students, 225 females and 138 males, students' ages were 9 and 10 years depending on their birthday date.

All primary and permanent teeth were examined for the presence of decay, missing or filling teeth / surfaces. The examination was carried out in the classroom under natural day light by one researcher to avoid interexaminer variation. A torch light was used when necessary. Instruments used in the examination were disposable plane mouth mirrors, sickle shaped mouth probes, cotton and disinfectant solution. After completing the examination, mean DMFT, DMFS, dmft and dmfs were calculated for the students together and separately for each sex. The mean $\mathrm{SiC}$ Index was also calculated as the mean DMFT and DMFS of the one third of the students with the highest caries scores. $^{(4,6)}$ It is used as a complement to the mean DMF value.

To calculate SiC Index:

1. Sort the individuals according to their DMF and dmf scores

2. Select the one third of the population with the highest caries values

3. Calculate the mean DMF and dmf for the sub group. ${ }^{(9)}$

Data were collected, summarized and analyzed using Statistical Package for Social Science (SPSS) program version 13.0 loaded on Pentium IV computer. Statistical analysis included descriptive (mean and standard deviation) and analytical (student's t-test) to compare between the traditional index and $\mathrm{SiC}$ index for males, females and the total sample. Significance was considered when $p<0.05$.

\section{RESULTS}

Mean DMFT for the total sample of both the traditional index and the $\mathrm{SiC}$ index were 3.86 and 5.34, respectively (Figure 1).

Mean DMFT for the male students were 3.89 and 5.43, respectively, while for the female students were 3.84 and 5.28, respectively. Mean DMFS for the total sample of both the traditional index and the $\mathrm{SiC}$ index were 6.24 and 9.68 , res- 
pectively (Figure 2). For males students, mean DMFS of both the traditional and $\mathrm{SiC}$ indices were 6.37 and 9.87 , respec- tively. For females students they were 6.16 and 9.56 , respectively.

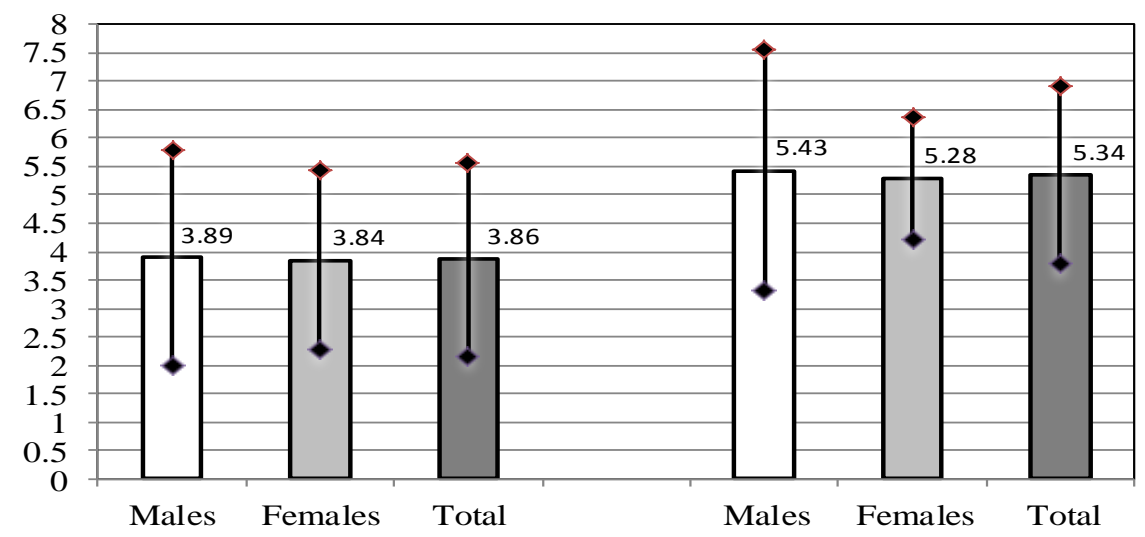

Figure (1): Descriptive statistics (mean $\pm \mathrm{SD}$ ) for males, females and total sample according to DMFT

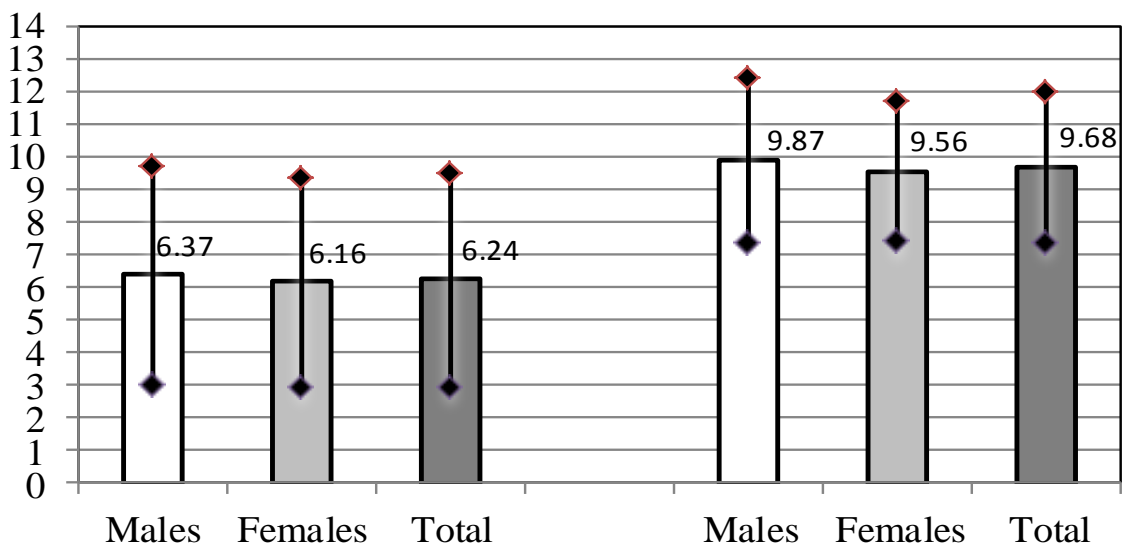

Figure (2): Descriptive statistics (mean $+\mathrm{SD}$ ) for males, females and total sample according to DMFS

Regarding dmft scores, means for the total sample of both the traditional index and the $\mathrm{SiC}$ index were 3.52 and 5.87, respectively (Figure 3). Mean dmft for males students were 3.67 and 6.04 , respectively. For females students, mean dmft of the traditional and $\mathrm{SiC}$ indices were 3.43 and 5.76, respectively.

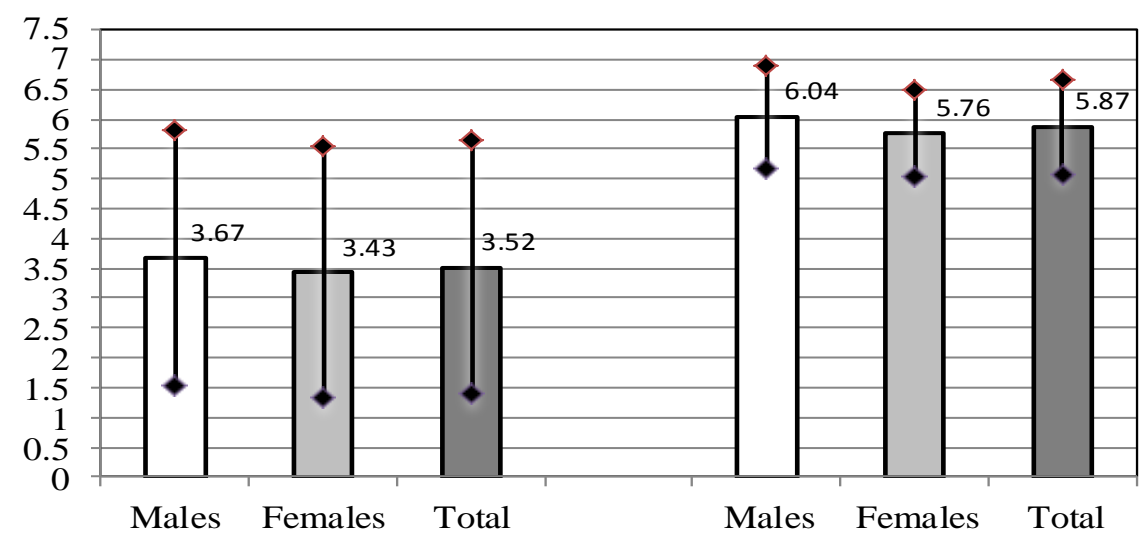

Figure (3): Descriptive statistics (mean $+\mathrm{SD}$ ) for males, females and total sample according to $\mathrm{dmft}$ 
While mean dmfs for the total sample of both the traditional index and the $\mathrm{SiC}$ index were 6.04 and 10.45 , respectively. Mean dmfs for male students were 6.33 and 10.93, respectively, and for female students, mean dmfs of both the traditional and the $\mathrm{SiC}$ indices were 5.87 and 10.16 respectively (Figure 4).

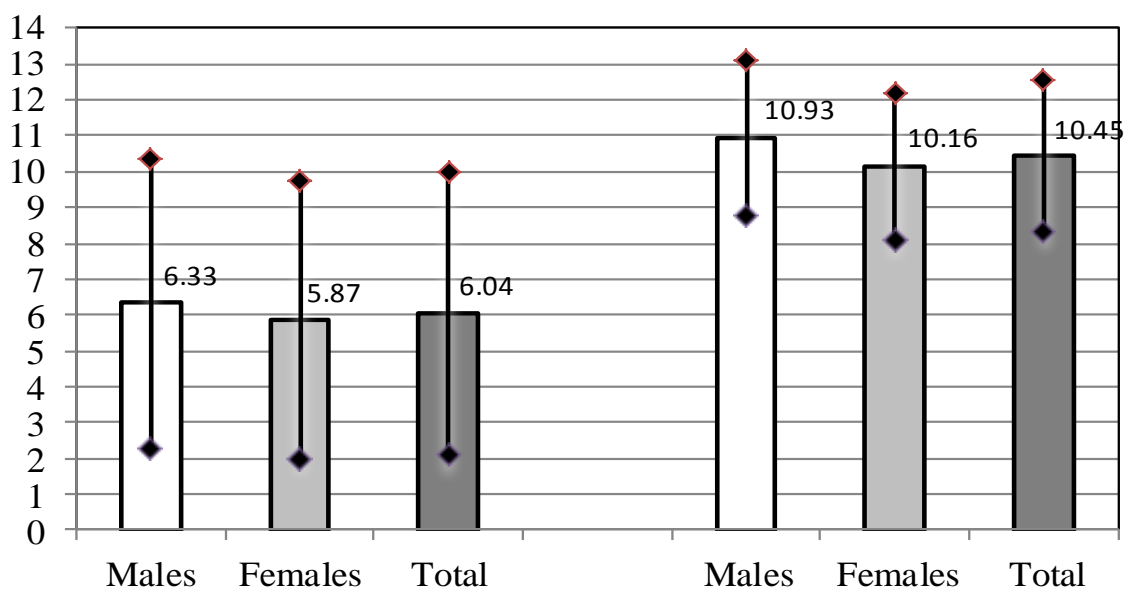

Figure (4): Descriptive statistics (mean $+\mathrm{SD}$ ) for males, females and total sample according to dmfs

Comparing statistically between the results of both traditional index and $\mathrm{SiC}$ index, all the differences were statistically significant at $(p<0.000)$ as shown in the Table.

Table: Comparison between traditional and SiC indices for males, females and total sample according to DMFT, DMFS, dmft and dmfs

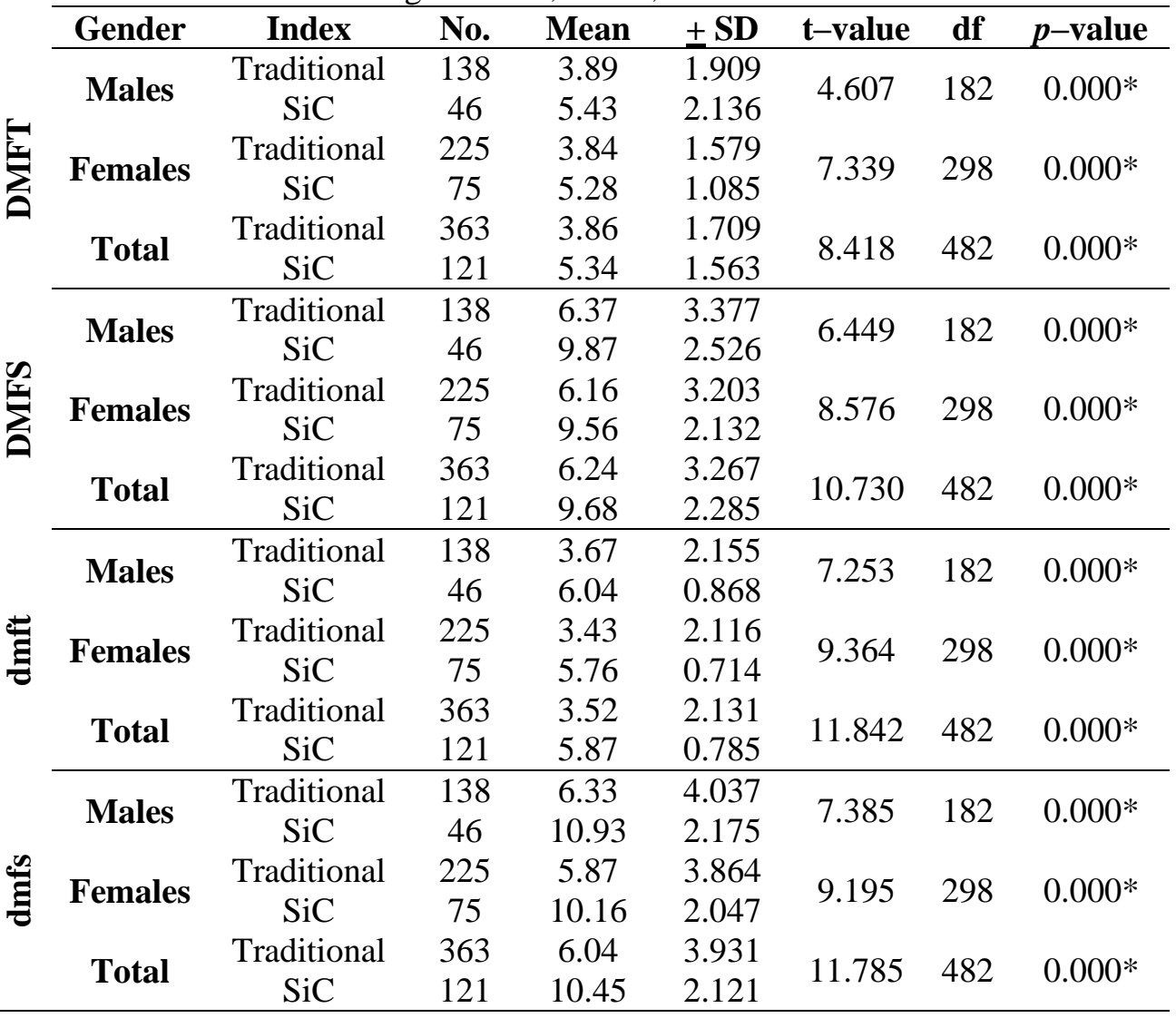

*significant difference exist at $p \leq 0.05$ 


\section{DISCUSSION}

This study investigated the caries prevalence among 9-10 years student in Mosul City Center using both the mean traditional and the $\mathrm{SiC}$ indices. The use of DMF and dmf indices has been an accepted practice for assessing the prevalence and severity of caries in a population. ${ }^{(10)}$ However, the epidemiologic changes in the dental caries picture during the last 2-3 decades, have made it increasingly evident that mean DMF and dmf values do not capture the polarized caries development with a more skewed distribution of caries. ${ }^{(11)}$ Mean DMF and dmf values are an average of all members of the population, irrespective of the distribution of the severity of the disease within the population.

As expected, the $\mathrm{SiC}$ index was significantly higher in all comparisons with DMF and dmf $(p<0.000)$ which is agreed with other studies. ${ }^{(11,12)}$ A comparison between the two indices, indicated there is a large children subgroup that presented with a higher caries rate than the targeted mean DMFT scores of 3.0. ${ }^{(13,14)}$ The mean DMFT from these data, compared to other studies' data, ${ }^{(15-17)}$ confirmed that dental caries remains a common chronic disease among Iraqi children and that they present with high prevalence rate and great mean DMFT indices. Although dental caries is largely preventable, it remains the most common chronic disease of children aged 9-10 years much of which remains untreated. This agreed with other studies. ${ }^{(10,}$ $18,19)$

The use of the SiC index that includes DMF can elucidate interpretations of findings, especially in situations where resources are limited for interventions. While mean scores provide a good measure of population disease levels, it is important to also look at those who might be carrying a significant burden of the dental disease experience in the population. ${ }^{(20)}$ To help in identifying high risk groups, it is recommended to calculate the $\mathrm{SiC}$ index at several levels. It has been suggested that $\mathrm{SiC}$ goal be established so that public health professionals can have two goals: Mean DMFT and SiC Indices. Bratthall ${ }^{(6)}$ suggested that $\mathrm{SiC}$ of less than 3.0 in 12year-old children as a global oral health goal to be achieved by the year 2015, while Marthaler et al ${ }^{(1)}$ suggested that $\mathrm{SiC}$ global goal of less than 5.0 be set for 15year olds rather than the WHO targeted age of 12- year olds.

The standard deviation of the $\mathrm{SiC}$ had about the same range as the corresponding ones of the DMF at both ages. In fact, the numbers of zero DMFT- counts add to the dispersion in the total sample whereas such 'caries free' subjects are not at all or rarely included in the upper tertile, that is in the $\mathrm{SiC}$ index. The relative variation, or coefficients of variation $(\mathrm{CV}$, standard deviation in percent of the average) of the $\mathrm{SiC}$ were accordingly much smaller than that of the DMFT because $\mathrm{SiC}$ index was much higher than the mean DMFT. Even in the case of the confidence limits, the higher relative precision of the $\mathrm{SiC}$ is maintained despite the fact that the number of children on which the $\mathrm{SiC}$ is based is by definition only one-third of the number of children available for the overall DMF. These findings show that the $\mathrm{SiC}$ is a fairly precise statistic for assessing caries in the most caries-prone third of children.

Practical experience in the epidemiological field work suggest another advantage of the $\mathrm{SiC}$ index. In children with low caries experience, who constitute the lower and middle tertiles, minute white fillings are frequently placed in pits and fissures. Part of these small restorations are likely to be overlooked. On the contrary, the upper tertile (providing the $\mathrm{SiC}$ ) will contain many children with extensive restorations and cavities, which are rarely overlooked. This means that in situations of low caries prevalence the overall DMF has a higher risk of underestimation than the $\mathrm{SiC}$ index.

Mean DMFT, DMFS, dmft and dmfs for females were slightly less than those for males, which is due to the fact that females care with their health and appearance more than males even at a young age. This agreed with other studies, ${ }^{(21-24)}$ but other studies found the opposite. ${ }^{(15,17)}$

No study is available about the association between the two indices, $\mathrm{SiC}$ value and DMFT, in Iraqi children. Furthermore, no study is found in the international literature about the factors affecting the $\mathrm{SiC}$ values of 9-10 years old children. This 
study can therefore help in designing future prospective studies.

With reference to the previous part of the discussion it would be expected that the relative stability of the subgroups in a special caries pattern could be used to conduct an early identification of the children with the highest caries prevalence and incidence, because they would be considered a special risk group for ending up in late adolescence with considerably higher caries rates than the remainder of the population.

\section{CONCLUSIONS}

The mean DMF values did not accurately reflect the skewed distribution of dental caries in Iraqi children leading to incorrect conclusions that the caries rate for the statewide population is under control. It is better to use SiC index instead of the traditional index. The data indicate there is a large proportion of children in Mosul City with poor oral health status, which only seems to improve very slowly. Decreasing caries prevalence in all countries is important to promote overall general health. Findings from this study should aid in two ways. At the community level, the study strongly points to the importance of introducing and retaining the community fluoridation program as an effective preventive measure. At the individual level the study identifies the need for more targeted efforts to reach children early.

\section{REFERENCES}

1. Marthaler T, Menghini G, Steiner M. Use of the Significant Caries Index in quantifying the changes in caries in Switzerland from 1964 to 2000. Community Dent Oral Epidemiol. 2005; 33: 159-166.

2. Marthaler TM, Brunelle J, Downer MC, Konig KG, Kunzel W, O'Mullane $\mathrm{DM}$, et al. The prevalence of dental caries in Europe 1990-1995. ORCA Saturday afternoon symposium 1995. Caries Res. 1996; 30: 237-255.

3. World Health Organization oral health country/area profile programme 2008.

4. Nishi M, Stjernsward J, Carlsson P, Bratthall D. Caries experience of some countries and areas expressed by the Significant Caries Index. Community Dent Oral Epidemiol. 2002; 30: 296301.

5. Burt BA. Prevention policies in the light of the changed distribution of dental caries. Acta odontologica Scandinavica, 1998, 56 (3):179-186.

6. Bratthall D. Introducing the Significant Caries Index together with a proposal for a new global oral health goal for 12-year-olds. Int Dent J. 2000; 50: 378-384.

7. Antunes JL, Narvai PC, Nugent ZJ. Measuring inequalities in the distribution of dental caries. Community Dent Oral Epidemiol. 2004; 32: 41-48.

8. Campus G Solinas G, Maida C, Castiglia P. The "Significant Caries Index" (SiC): a critical approach. Oral health prev dent, 2003; 1(3):171-178.

9. Nishi M, Bratthall D, Stjernsward J. How to calculate the Significant Caries Index (SiC Index). WHO collaborating centre. 1.0; 2001-03-6.

10. Dye BA, Tan S, Smith V, Lewis BG, Barker LK, Yhornton-Evans G. Trends in oral health status: United States, 1988-1994 and 1999-2004. National Center for Health Statistics. Vital Health Stat, 11. 2007. Publication No. (PHS) 2007-1698.

11. Ditmyer M, Dounis G, Mobley C and Schwarz E. Inequalitiez of caries experience in Navada youth expressed by DMFT index vs. Significant caries index $(\mathrm{SiC})$ over time. BMC oral health 2011; 11:12.

12. Namal N, Yuceokur AA and Can G. Significant caries index values and related factors in 5-6-years-old children in Istanbul, Turkey. Eastern Mediterranean Health J. 2009; 15(1): 178184.

13. World Health Organization. Oral Health Information Systems: Oral Health Surveillance, Geneva, Switzerland, 2010.

14. World Health Organization. Significant Caries Index, Geneva, Switzerland. 2010.

15. Khamrco TY, Salman FD. Prevalence of dental caries among primary school children age 6-12 years old in Mosul City center/ Ninevah. Iraqi Dent J. 
2001; 27: 65-82.

16. Khamrco TY, Makani LA, Jazrawi KH. Dental caries changes between (1989) and (2001) in children aged (314) years in KasaFakhra and AlShamsiat villages, Ninevah Governorate, Iraq. Al-Rafidain Dent J. 2002; spec iss(2): 269-278.

17. Al-Jumaili KA, Al-Naimi RJ, Jazrawi KH. Dental caries experience, prevalence and severity in 13-15 years old students in Mosul City center. AlRafidain Dent $J$. spec iss for the 5th scientific conference of Dentistry College, Apr. 2011;184-192.

18. Petersen PE, Bourgeois D, Ogawa H, Estupinan-Day S, Ndiaye C. The global burden of oral diseases and risk to oral health. Bull World Health Organ. 2005; 83(9): 661-669.

19. Office of the Surgeon General. Oral health 2000: Fact and Figures. Accessed in February 20, 2011.

20. Sheiham A, Sabbah W. Using universal patterns of caries for planning and evaluating dental care. Caries Res. 2010; 33: 159-166.

21. Gasgoos SS. Caries severity of primary teeth among kindergarten children in Mosul City using International Caries Detection and Assessment System. Al-Rafidain Dent J. 2011; 11(1): 183-193.

22. Salman FD, Gasgoos SS, Qasim AA. Dental caries risk indicators by using International Caries Detection and Assessment System in Mosul City. AlRafidain Dent J. 2011;11(1): 113-123.

23. Al-Shalan TA. Saudi parents knowledge of and attitude towards the prevention of dental caries. Saudi Dent J. 2001; 15(1): 27-32.

24. Al-Wazzan KA. Dental caries prevalence in 6-7 years-old school children in Riyadh region: A comparative study with the 1987 Oral Health Survey of Saudi Arabia Phase 1. Saudi Dent J. 2004; 16(2): 54-60. 